\title{
The social elite: Habitat heterogeneity, complexity and quality in granite inselbergs influence patterns of aggregation in Egernia striolata (Lygosominae: Scincidae)
}

\author{
DAMIAN R. MICHAEL, * ROSS B. CUNNINGHAM AND DAVID B. LINDENMAYER \\ Fenner School of Environment and Society, The Australian National University, Canberra, ACT 0200, \\ Australia (Email: damian.michael@anu.edu.au)
}

\begin{abstract}
Habitat heterogeneity, structural complexity and habitat quality are key features of the environment that drive species' distribution and patterns of biological organization. Traditionally, pattern-based studies have focused on faunal responses to biological systems. However, the influence of non-biological environments such as insular rock outcrops on patterns of vertebrate distribution is conceivably as important, but has received less attention. Granite inselbergs are a naturally heterogeneous and spatially-limited habitat. As such, they provide an opportunity for investigating whether environmental attributes influence social behaviour in animals that use these kinds of habitat, particularly lizards that are well adapted to saxicoline environments. We applied ecological theory to investigate the influence of habitat heterogeneity, structural complexity and habitat quality on patterns of home-site occupancy in the crevice skink Egernia striolata (Lygosominea: Scincidae) from insular granite outcrops located within fragmented agricultural landscapes. We compared home-site occupancy among solitary juveniles, solitary adults and lizard aggregations. We found significant differences in home-site occupancy between aggregations and solitary lizard outcrop attributes measured at multiple spatial scales. The probability of a home-site being occupied by an aggregation increased where large rock masses were present, on northern aspects near the core of the outcrop and in structurally variegated landscapes. Significantly more aggregations occupied home-sites surrounded by high boulder cover and crevice microhabitat. We provide evidence that geophysical attributes of granite inselbergs and landscape context can influence patterns of lizard aggregation. Thus, we clearly document the environmental correlations of variability in sociality among subpopulations of Egernia striolata.
\end{abstract}

Key words: Egernia, granite inselberg, habitat complexity, heterogeneity, lizard sociality.

\section{INTRODUCTION}

Understanding species' distribution patterns and levels of biological organization can be guided by ecological concepts such as habitat heterogeneity theory, structural complexity theory (MacArthur \& MacArthur 1961; Morrison et al. 2006) and spatial and temporal variability in habitat quality (Bennett et al. 2006; Lindenmayer \& Fischer 2006). These concepts have been applied widely to investigate relationships between vegetation-related variables and vertebrate diversity (Tews et al. 2004; Morrison et al. 2006), although a clear use of terminology is necessary to adequately relate species responses to habitat structure (Hall et al. 1997). The terms 'heterogeneity' and 'complexity' are often used synonymously in the literature. In this paper, habitat heterogeneity refers to patchiness on a horizontal plane, whereas habitat complexity refers to vertical stratification (August 1983; Lindenmayer \& Fischer 2006). We define habitat quality as

${ }^{\star}$ Corresponding author.

Accepted for publication October 2009. the ability of the environment to provide conditions appropriate for individuals and populations to persist over time, and this should be explicitly linked to demographic process to have any useful and measurable meaning (Hall et al. 1997; Lindenmayer \& Fischer 2007). We examine these concepts to help understand environmental correlates of variability in sociality among subpopulations of Egernia striolata inhabiting insular granite inselbergs.

Most pattern-based studies examining vertebrate diversity have focused on birds and mammals in biotic environments (Morrison et al. 2006). However, nonbiological environments such as granite inselbergs can be equally heterogeneous and just as structurally complex as biotic systems (Twidale \& Vidal Romani 2005). However, granite inselbergs have received little attention in temperate regions of the world (Burke 2003) and some taxa in particular, such as reptiles, have been poorly studied (Withers \& Edward 1997). This is despite the fact that these kinds of environments can be extremely species-rich. Recently, Michael et al. (2008) studied patterns of reptile diversity in granite inselbergs and found positive 
relationships with habitat heterogeneity and structural complexity. Furthermore, environmental heterogeneity can influence the spatial arrangement and type of social interactions that occur among individuals (Stamps 1977; Gregory 1984). However, few studies have investigated the influence of environmental attributes on behaviour, in particular, complex sociality in lizards. Thus, the influence of environmental heterogeneity on patterns of social organization in reptiles represents an important knowledge gap in the ecological and conservation literatures.

With respect to vertebrates, social behaviour has traditionally been associated with mammalian or avian groups (Stamps 1977) although, it is evident that sociality is widespread in some groups of reptiles (Masters \& Shine 2003; O’Connor \& Shine 2003; Osterwalder et al. 2004; Chapple \& Keogh 2006). One lineage, in particular, which exhibits substantial diversity in social organization, is the Australian scincid genus Egernia (Gardner 1999; Chapple 2003). More than half of the 32 described Egernia species exhibit some degree of sociality, ranging from small 'nuclear families' consisting of a breeding pair and their annual offspring (e.g. Egernia saxatilis, O'Connor \& Shine 2003 and E. striolata Bonnett 1999) to large, stable groups comprising of highly-related, extended family members (e.g. Egernia cunninghami Stow et al. 2001; Stow \& Sunnucks 2004a,b; Egernia frerei Fuller et al. 2005; Egernia kingii Masters \& Shine 2003; Egernia stokesii Gardner et al. 2001, 2002; Duffield \& Bull 2002). This diversity in social systems provides an ideal opportunity for investigating factors influencing the variability of complex sociality in lizards, which in turn, could broaden our understanding of social organization in other rock-dwelling vertebrates such as pikas Ochotona princeps and rock hyraxes Procavia capensis (Mares 1997).

Several hypotheses have been suggested to explain complex sociality in Egernia. These include neonatal protection from aggressive interactions by conspecifics (O’Connor \& Shine 2003; Langkilde et al. 2007), protection from predators (Masters \& Shine 2003), enhanced vigilance (Lanham \& Bull 2004) and the maintenance of inheritable high-quality habitat (Langkilde et al. 2007). Furthermore, O'Connor and Shine (2003) suggested that group size and composition may be related to habitat. For example, large rock outcrops with large, deep crevices are able to accommodate large groups (e.g. E. cunninghami, Stow \& Sunnucks 2004a). Parental protection of juveniles against infanticidal attacks by conspecifics is a plausible explanation for parent-offspring associations in species found in small family groups (Langkilde et al. 2007). Furthermore, habitat variability and quality could also provide complimentary explanations for the development of complex social systems in this lineage (Duffield \& Bull 2002; Chapple \& Keogh 2006).
To test the hypothesis that aggregate patterns in Egernia are influenced by environmental attributes, we present a detailed case study of free living E. striolata inhabiting insular granite outcrops in southeastern Australia. Granite outcrops are a naturally patchy and spatially-limited resource in many environments around the world (Porembski \& Barthlott 2000), which vary considerably in habitat heterogeneity (relative abundance of rock and vegetation cover), structural complexity (landform type and composition of granite masses) and habitat quality (rock and vegetation resource abundance). Hence, inter- and intra-outcrop variability provides an ideal opportunity for examining proximate factors that may influence patterns of social organization (Langkilde et al. 2007). In this study, we explore the relationship between geophysical attributes of granite outcrops and patterns of group aggregation in $E$. striolata. We used a novel theoretical approach to examine home-site occupation by solitary lizards versus aggregated lizards in relation to: (i) outcrop heterogeneity; (ii) inter- and intra-outcrop structural complexity; and (iii) home-site habitat quality. We hypothesized that environmental attributes will influence aggregate behaviour, with groups of lizards occupying the largest home-sites in better quality habitat and within the core areas of the most structurally complex landforms.

\section{METHODS}

\section{Study species}

The tree crevice skink E. striolata is a medium-sized viviparous skink (snout-vent length up to $119 \mathrm{~mm}$, Wilson \& Swan 2008), which utilizes trees and rock outcrops in forest and woodland vegetation types in eastern Australia (Cogger 2000; Wilson \& Swan 2008). It is reported to be solitary and aggressively territorial in some environments (Bustard 1970). For example, in the Pilliga region of New South Wales, solitary lizards were found sheltering under the bark of exfoliating Callitris sp. (Bustard 1970). Similarly, solitary lizards were found in arboreal populations from lowland woodland habitats in the South-western Slopes bioregion of New South Wales (Cunningham et al. 2007). In contrast, saxicolous populations in the same bioregion form small groups (D. Michael, pers. obs., 2006), in a similar manner to South Australian saxicolous populations (Bonnett 1999). It is likely, given the diversity in social systems within E. striolata, arboreal and saxicolous populations may represent different taxonomic entities. In this study, we focused only on saxicolous populations.

\section{Study area}

We surveyed granite outcrops within the southern half of the South-western Slopes biogeographical region of New South 


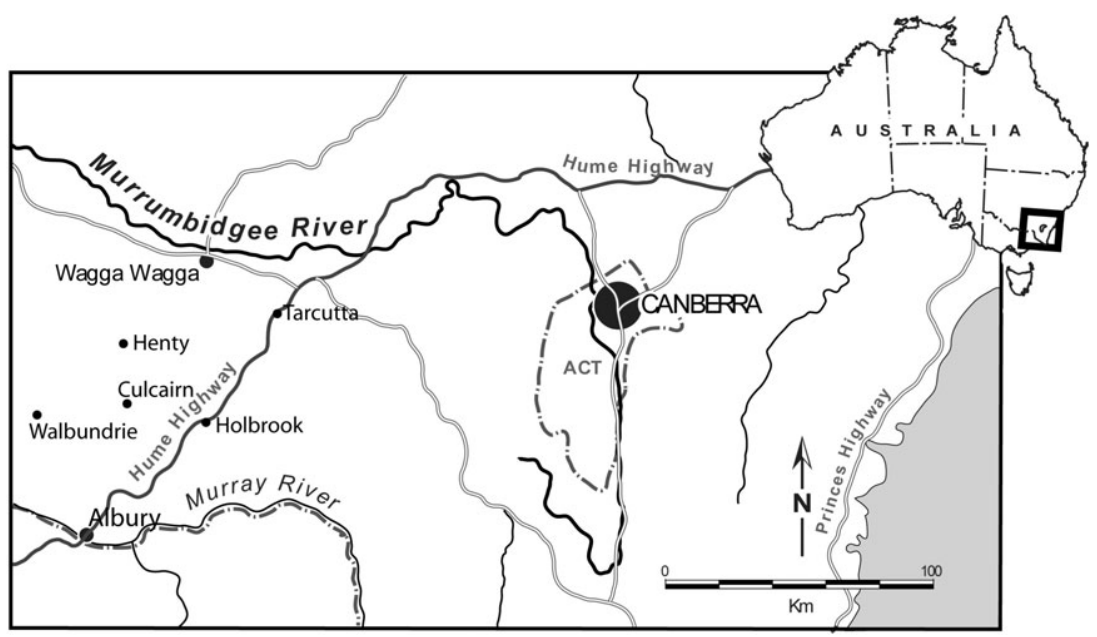

Fig. 1. Location of the study area in the South-western Slopes biogeographical region of New South Wales, south-eastern Australia.

Wales. Our study area was bordered by the towns of Tarcutta $\left(35^{\circ} 16^{\prime} \mathrm{N}, 147^{\circ} 44^{\prime} \mathrm{E}\right)$ in the north; Albury $\left(36^{\circ} 04^{\prime} \mathrm{N}\right.$, $\left.146^{\circ} 54^{\prime} \mathrm{E}\right)$ in the south; Holbrook $\left(35^{\circ} 41^{\prime} \mathrm{N}, 147^{\circ} 18^{\prime} \mathrm{E}\right)$ in the east and Walbundrie $\left(35^{\circ} 41^{\prime} \mathrm{N}, 146^{\circ} 43^{\prime} \mathrm{E}\right)$ in the west (Fig. 1). Our study area was characterized as a variegated, agricultural landscape (sensu McIntyre \& Hobbs 1999) and ranged in elevation from $150 \mathrm{~m}$ a.s.l. in the west, to $450 \mathrm{~m}$ a.s.l. in the east. Insular granite outcrops are a dominant geological feature of the region. They vary in size, shape and condition, and depending on soil type, support tree species such as white box Eucalyptus albens, Blakely's red gum Eucalyptus blakelyi, tumbledown red gum Eucalyptus dealbata, white cypress pine Callitris glaucophylla and currawang Acacia doratoxylon. Native understorey and ground cover species are highly depleted and compositionally modified as a result of the long history of grazing and agricultural practices in the region.

\section{Study design}

We surveyed lizards in 44 granite landforms (inselbergs) located within agricultural landscapes and which ranged in size from small $(<1$ ha, $n=7)$, medium $(1-10$ ha, $n=32)$ to large ( $>10$ ha, $n=5)$. We categorized outcrops based on geomorphology and the spatial arrangement of rock masses (sensu Twidale \& Vidal Romani 2005). Thus, we recognized four inselberg landforms: (i) bornhardts; (ii) nubbins; (iii) koppies; and (iv) scattered tors (Fig. 2).

\section{Survey protocol}

We surveyed lizards on each outcrop between October 2006 and February 2007 on clear days above $25^{\circ} \mathrm{C}$ and between 09.00 and 14.00 hours using an area-constrained (4 ha) search protocol. A $200 \mathrm{~m} \times 200 \mathrm{~m}$ grid encompassed the entire outcrop on 34 occasions, whereas a $400 \mathrm{~m} \times 100 \mathrm{~m}$ transect was established on the remaining larger outcrops straddling the crest and opposite slopes, thereby encompassing all aspects and topographic positions. First, we recorded basking animals and those sheltering within rock crevices. We then inspected additional habitats including beneath surface rocks and fallen timber, and behind exfoliating bark. We did not attempt to prize open exfoliations or flakes. Instead, where possible, we inspected them by using a mirror to reflect torch light into the crevice. To adequately survey all shelter-sites, we inspected difficult to reach crevices using a $10-\mathrm{m}$ extension ladder and in some cases with the aid of rock-climbing equipment. We assigned individuals to two age cohorts, immature lizards (e.g. first- and second-year offspring) and adults, by visually estimating body length. We classified lizards as being in 'aggregation' if they were sheltering within the same crevice or were observed basking on the same rock (usually within $2-4 \mathrm{~m}$ of other individuals). Without prior knowledge of home-range size and group stability in our study area, we were reluctant to assume our aggregations consisted of family members. Furthermore, we were unable to infer group structure (sex ratios) from our observational data. Therefore, to avoid misinterpretation, we use the term aggregation rather than infer 'family groups' or 'social structure'.

\section{Measurement of covariates}

We assessed heterogeneity at two scales. At a patch scale (4-ha survey grid), we measured the per cent cover of rock types based on volume: (i) 'rocks' = less than $0.5 \mathrm{~m}^{3}$ (corresponding with the kinds of objects that could feasibly be rolled over); (ii) 'boulders' $=0.5$ to $2 \mathrm{~m}^{3}$; (iii) 'pillars' $=2$ to $5 \mathrm{~m}^{3}$; (iv) 'blocks' $=5$ to $10 \mathrm{~m}^{3}$; and (v) 'domes' = more than $10 \mathrm{~m}^{3}$, as well as ground cover attributes (e.g. grasses, forbs, leaf litter, bare earth and logs). At a landscape-scale, we assessed the context in which each outcrop was situated within a $1000-\mathrm{m}$ radius of each outcrop. We differentiated between outcrops located in either of two patch/matrix land- 
(a)

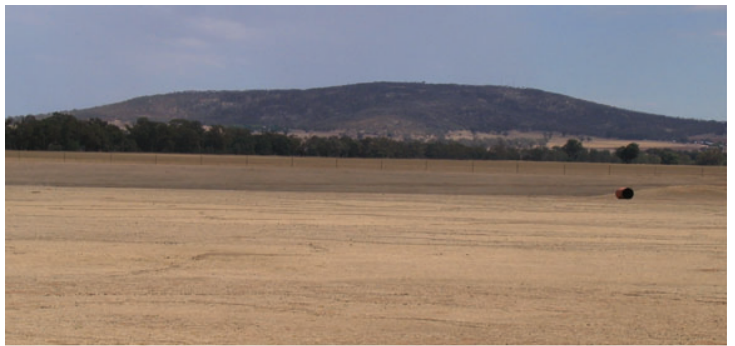

(b)

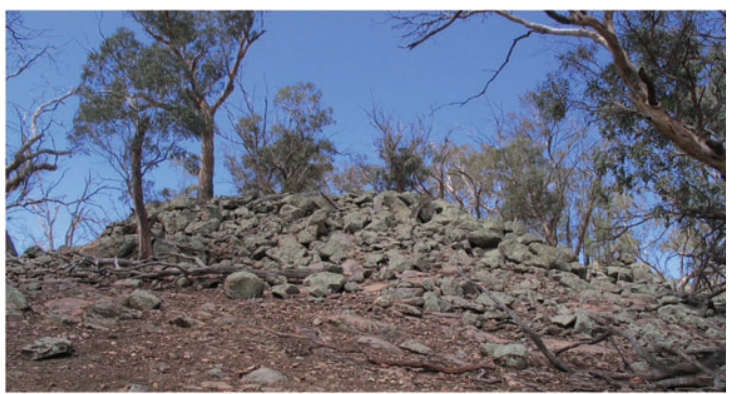

(c)

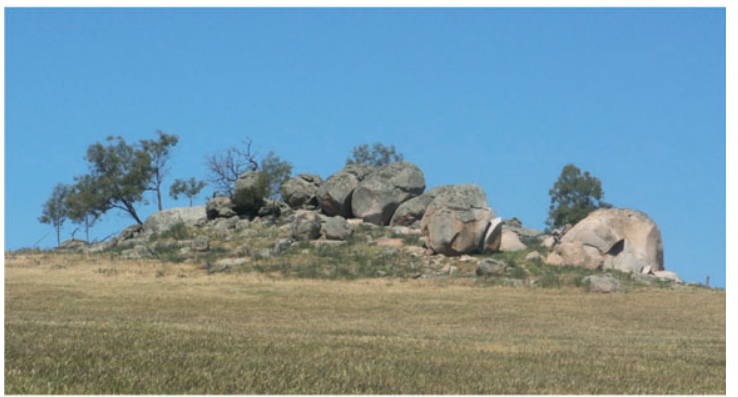

(d)

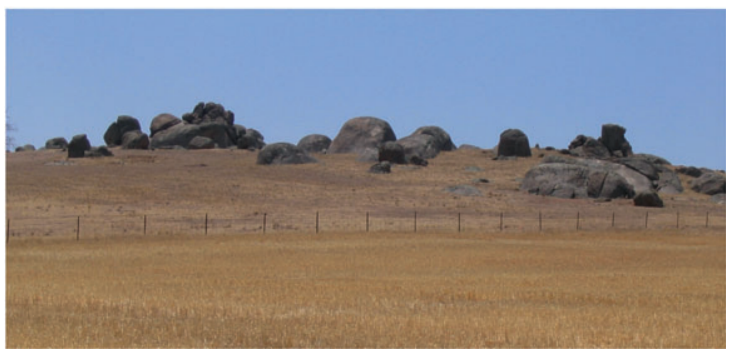

Fig. 2. Granite inselberg landforms surveyed in the Southwestern Slopes of New South Wales: (a) bornhardt, (b) nubbin, (c) castle koppie and (d) scattered tors.

scape contrasts: (i) outcrops surrounded by a highly disturbed and relatively homogenous, human-modified matrix, that is, landscapes containing less than $2 \%$ of the original overstorey vegetation and supporting cereal crops or annual pasture; and (ii) outcrops surrounded by a moderately disturbed, variegated matrix, that is, landscapes containing more than $10 \%$ of the original overstorey vegetation, native tree plantings and both native and exotic pasture.

We assessed structural complexity in two ways. First, we classified inselbergs by landform. Second, we recorded the relative per cent cover of the five rock types mentioned above on each outcrop. These scores were then converted to a cumulative measure of structural complexity, ranging from 1 - simple outcrop (dominated by one structural class) to 5 - complex outcrop (outcrops containing all five structural classes). Mid-range values relate to outcrops with corresponding complexity scores.

To assess habitat quality, we recorded the number of shelter-sites, shelter-type (e.g. crevice or flake), shelter aspect and shelter orientation (e.g. horizontal, diagonal or vertical) of each home-site occupied by solitary lizards and aggregations. In addition, we assigned each home-site a 'real estate' score based on a four by four classification scheme to examine home-site characteristics in detail. One dimension incorporated four basal area categories: (i) $<0.5 \mathrm{~m}^{2}$; (ii) $>0.5-$ $2 \mathrm{~m}^{2}$; (iii) 2-5 $\mathrm{m}^{2}$; and (iv) $>5 \mathrm{~m}^{2}$, and the second dimension incorporated four identical height categories. Thus, 16 real estate combinations were possible, ranging from small 'rocks' with a real estate of 1.1 to large 'blocks' with a real estate of 4.4. This classification scheme captured diversity in rock formations, although a high correlation between basal area and height enabled the 16 combinations to be condensed to four height categories in subsequent analysis. In addition, we measured a range of explanatory variables within a $10-\mathrm{m}$ radius of each home-site, including the per cent cover of rock types, projected canopy and understorey cover (shade effects) and ground cover attributes (e.g. native and exotic forbs, native and exotic grasses, leaf litter and bare earth).

\section{Statistical analysis}

We explored relationships between aggregate abundance and habitat heterogeneity using generalized linear models (McCullagh \& Nelder 1989). We modelled aggregations in two stages, first by considering whether the home-site was occupied by an aggregate or not and second (given occupancy by a solitary individual), whether the solitary individual was an adult or not. We used linear logistic regression models to estimate effects of habitat variables. We constructed models first by fitting explanatory variables separately, ignoring all other variables, and second by jointly considering all likely candidate variables. We selected the most parsimonious models using Akaike and Schwartz Information Criteria for all possible regressions. In all cases, we checked inferences by refitting models using the generalized linear mixed models framework with farm $(n=24)$ as a random effect to control for non-independence among outcrops situated within the same management unit.

\section{RESULTS}

\section{Summary statistics}

We recorded a total of 480 individual E. striolata from 44 inselbergs, representing observations of 102 aggregations, 119 solitary adults and 98 solitary immature lizards. Four outcrops contained no lizards, the number of aggregations per inselberg ranged from zero to nine, and group sizes ranged from two to four. We observed lizard pairs on 61 occasions $(60 \%)$, aggregations of three on 33 occasions (32\%) and aggregations of four on eight occasions ( $8 \%$ ). 


\section{Relationship between habitat heterogeneity and aggregation abundance}

Using Poisson regression analysis, we found aggregate abundance was significantly related to outcrop and landscape heterogeneity. The most parsimonious mixed model revealed the predicted number of lizard aggregations was positively related to both the per cent cover of granite pillars $(P<0.01)$ and landscape context $(P<0.001)$, and negatively related to exotic grass cover $(P<0.01)$. As pillar cover increased and exotic grass cover decreased, the predicted number of aggregations increased. Likewise, more aggregations were predicted to occur on outcrops situated in variegated landscapes than outcrops situated in highly modified, homogenous landscapes.

\section{The relationship between outcrop complexity and lizard aggregation patterns}

We found that the probability of a home-site being occupied by an aggregation of lizards differed significantly among landforms $(P=0.003)$. Home-site occupancy by an aggregation was highest in tor landforms and lowest in nubbin landforms (Fig. 3). We observed twice as many solitary adults on bornhardts and three times more solitary adults on nubbins than aggregated lizards. We found no significant difference in home-site occupancy among landforms between solitary adults and immature lizards $(P=0.38)$.

We found that the height of a home-site had a significant effect on whether a home-site was occupied by an aggregation of lizards or a solitary lizard $\left(\chi_{3}^{2}=28.5, P<0.001\right)$. The probability that a homesite would be occupied by an aggregation increased in relation to rock height (Fig. 4). Furthermore, we found a high probability that a solitary lizard occupying a low (and hence smaller) home-site would be a subadult, rather than a juvenile lizard $\left(\chi_{3}^{2}=11.4\right.$, $P=0.01$ ).

We found a significant relationship among aggregate and solitary lizard and home-site real estate scores $\left(\chi_{28}^{2}=53.32, P=0.003\right)$. More than $70 \%$ of all lizard aggregations were observed on home-sites with high real estate combinations (i.e. 3.3, 3.4 and 4.4). In contrast, $55 \%$ of immature lizard observations and $65 \%$ of solitary adult observations were from home-sites with comparatively low real estate combinations. Solitary adults and immature lizards were more abundant on home-sites with a real estate score of 1.1 or 2.2.

\section{Influence of habitat quality on patterns of lizard aggregation}

Overall, we found that the habitat used by aggregated lizards differed significantly from that of solitary adults a)
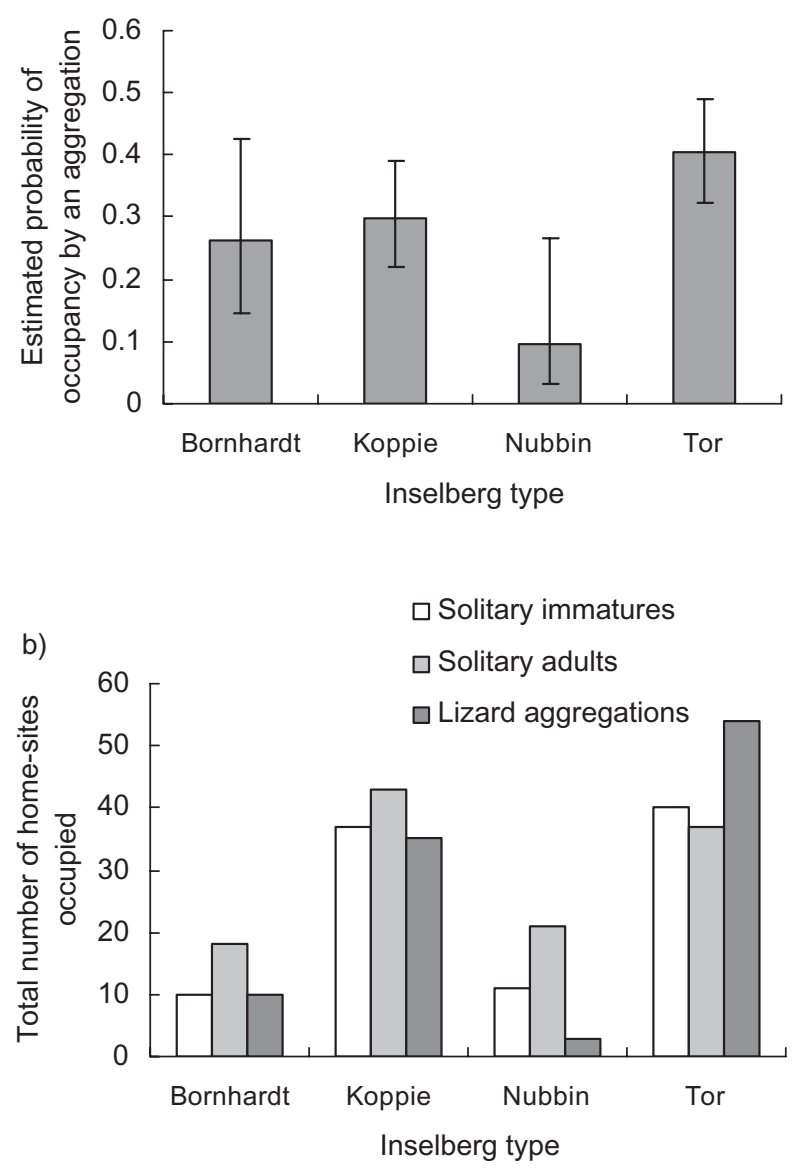

Fig. 3. (a) The estimated probability different inselberg types will be occupied by an aggregation of lizards; and (b) The total number of home-sites occupied by lizard aggregations, solitary immature and solitary adult Egernia striolata.

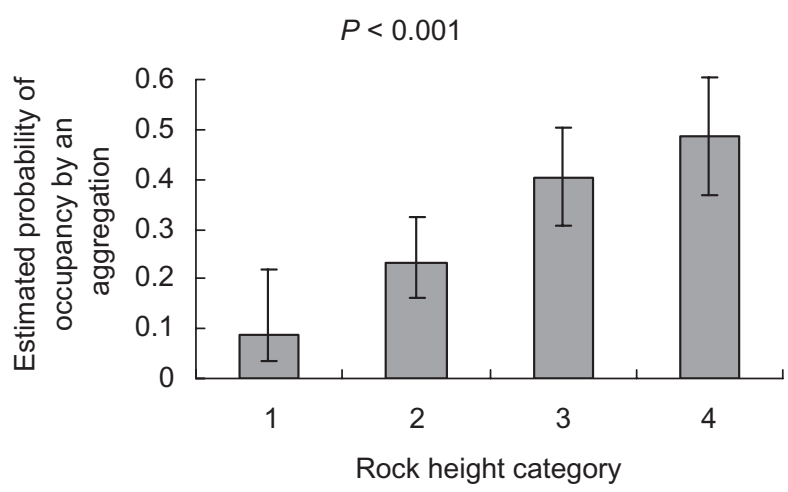

Fig. 4. The estimated probability a home-site will be occupied by an aggregation of Egernia striolata in relation to rock height.

and solitary immature lizards. Chi-squared tests on individual habitat characteristics revealed the per cent cover of boulders $\left(\chi_{2}^{2}=10.78, P=0.029\right)$ and number of crevices $\left(\chi_{2}^{2}=4.09, P=0.018\right)$ differed significantly 

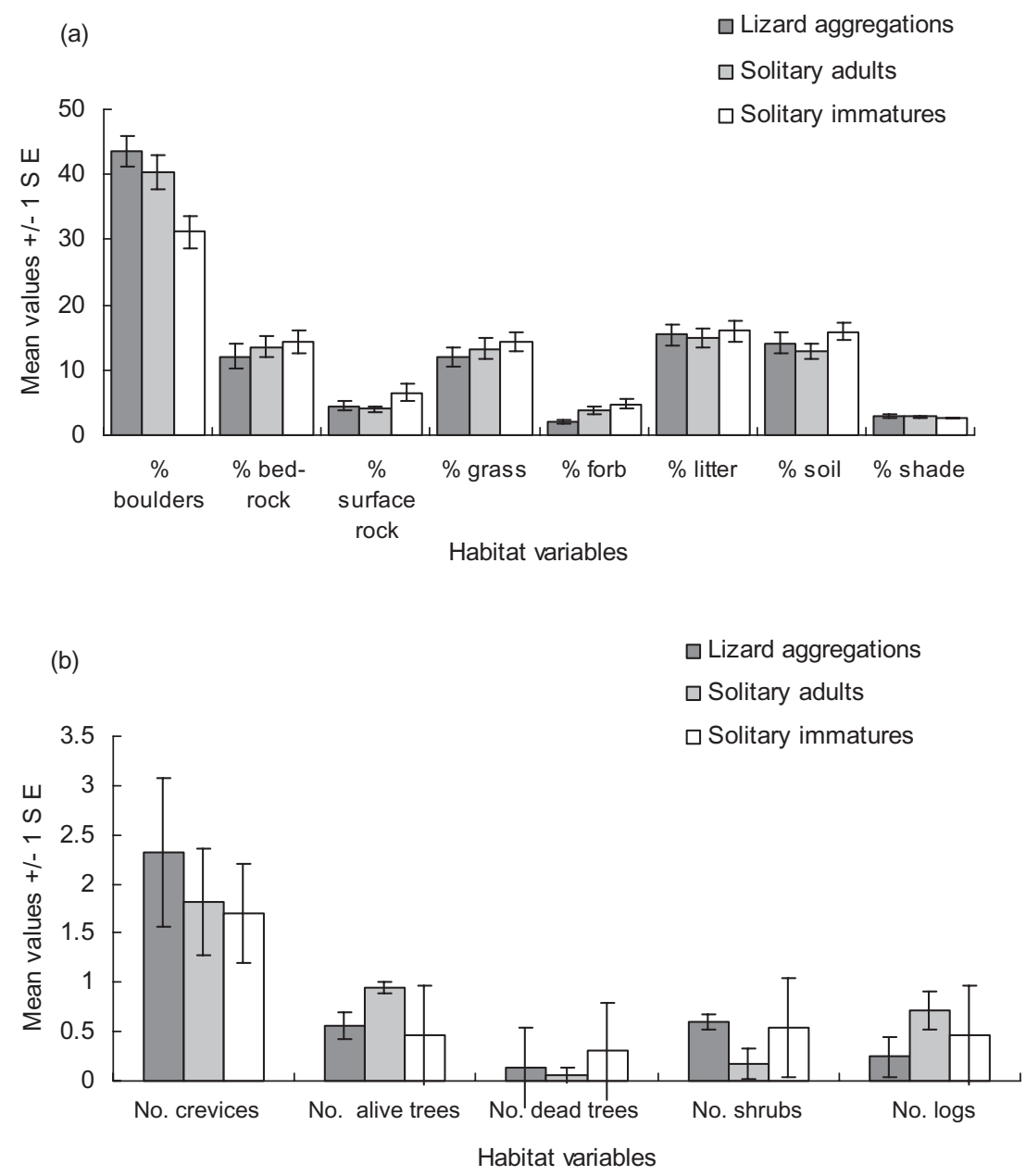

Fig. 5. Mean values of (a) categorical variables, and (b) continuous variables surrounding home-sites occupied by lizard aggregations, solitary adults and solitary immature lizards.

between lizard classes (Fig. 5). The number of crevices and per cent cover of boulders surrounding the homesite of aggregated lizards was greater than home-sites occupied by solitary lizards. In addition, although not significant, the surrounding microhabitat of homesites occupied by solitary immature lizards contained a greater per cent cover of bedrock, surface rocks, grasses, forbs, bare soil and dead trees (Fig. 5).

\section{The influence of topography on the spatial distribution of Egernia aggregations}

We found that both the topographic position $\left(\chi_{3}^{2}=12.7, P=0.005\right)$ and the aspect $\left(\chi_{4}^{2}=15.1, P=\right.$ $0.004)$ in which lizard home-sites were situated within an outcrop had a significant effect on whether they were occupied by an aggregation or not. A greater proportion of lizard aggregations occupied homesites near the core (and hence peak) of the outcrop and on the northern aspects. Solitary immature lizards were significantly abundant on north facing aspects $\left(\chi_{4}^{2}=14.9, P=0.005\right)$, although home-sites occupied by this age cohort were often located on the lower slopes, and near the edge of the outcrop.

\section{DISCUSSION}

Over the past decade there has been a diverse literature published on the ecology, life history and behaviour of the Egernia group (reviewed by Chapple 2003). These studies have primarily focused on two topics: (i) group structure and stability (Gardner et al. 2001; Masters \& Shine 2003; O'Connor \& Shine 2003; Osterwalder et al. 2004; Fuller et al. 2005; Chapple \& Keogh 2006); and (ii) kin discrimination (Main \& Bull 1996; Bull et al. 2001; O'Connor \& Shine 2005). Langkilde et al. (2007) suggested the main benefit of forming stable social groups in E. saxatilis is the care afforded to offspring by parents and not access to high quality, inheritable territories. Others have suggested that 
social groupings are not driven by habitat attributes (Osterwalder et al. 2004), nor are they restricted to specific habitat type such as rock outcrops (Fuller et al. 2005). However, environmental factors can influence genetic structure and demographic processes (Stow et al. 2001). Below, we discuss patterns of aggregate behaviour in E. striolata in relation to three environmental attributes: habitat heterogeneity, structural complexity and habitat quality.

\section{Outcrop and landscape heterogeneity}

Habitat heterogeneity theory assumes that structurally diverse environments may provide more niches, thereby increasing species diversity (Tews et al. 2004). We extend this concept to explain patterns of aggregation in Egernia. We found group formation increased significantly in structurally diverse environments and over multiple spatial scales. Among outcrops, the number of aggregations encountered on an outcrop increased in response to granite 'pillar' cover. Likewise, more aggregations were predicted to occur on outcrops situated in variegated landscapes than outcrops situated in highly modified landscapes, suggesting matrix conditions may influence meta-population dynamics in E. striolata. Other studies have found habitat modification to have a profound affect on the dispersal ability and genetic structure of saxicolous reptile populations. For example, Stow et al. (2001) found family groups of E. cunninghami inhabiting outcrops in heavily cleared environments to be more genetically structured than those living in near natural environments. Berry et al. (2005) found saxicolous populations of Oligosoma grande to be more genetically structured in outcrops surrounded by introduced pasture than outcrops surrounded by native tussock grass.

We also found a topographic partitioning effect among social groupings, whereby lizard aggregations occupied core-area home-sites compared with solitary immature lizards that occupied peripheral home-sites. This pattern raises some interesting insights into subpopulation stability. It is plausible that dispersing lizards occupy territories peripheral to established lizard groups in wait of such time when breeding pairs dissolve, thereby providing solitary lizards with an opportunity to establish a pair bond. Acquisition of vacated high quality territories by 'floater' individuals has been reported in avian studies (Zack \& Stutchbury 1992).

\section{Habitat complexity}

Habitat complexity theory assumes that species diversity increases in response to increasing habitat com- plexity (MacArthur \& MacArthur 1961; Tews et al. 2004). The intraspecific variability in patterns of aggregation documented in this study followed a similar trend, whereby aggregate abundance increased in response to structural complexity. The four granite landforms examined in this study varied considerably in structural complexity (Twidale \& Vidal Romani 2005). Bornhardts and nubbins are structurally homogenous inselbergs, whereas koppies and tors are structurally variable (Fig. 2). These two landforms are the reduced remnants of much larger bornhardts (Twidale \& Vidal Romani 2005) and therefore, contain greater diversity of rock sizes and crevice microhabitat. Hence, we found lizard aggregations to be most abundant on tor landforms and least abundant on nubbins (Fig. 3). A similar pattern was evident within outcrops. Lizard aggregations were more likely to occupy the tallest home-sites (Fig. 4). In contrast, solitary immature lizards were found to occupy low home-sites. This suggests immature lizards (potential dispersers or orphans), are either unable to secure a home-site already occupied by an established group or have not yet formed a pair bond. Alternatively, immature lizards may simply be able to occupy rocks with smaller and fewer crevices than larger adult lizards (O'Connor \& Shine 2003). Territorial behaviour and aggression towards conspecifics is well documented in this species (Bustard 1970; Bonnett 1999; Bull et al. 2001). Thus, groups of lizards may be better equipped to defend a large home-site territory than a solitary individual. Alternatively, the risk of predation by large common elapids such as the eastern brown snake Pseudonaja textilis (Michael et al. 2008) are significantly reduced on tall, steep-sided granite masses potentially contributing to group stability and aggregate behaviour.

\section{Habitat quality}

The broad similarity in habitat attributes surrounding home-sites occupied by lizard aggregations and solitary individuals is consistent with a similar study on $E$. saxatilis by Langkilde et al. (2007). We found the only microhabitat variables to differ significantly between the lizard aggregations and individuals were the amount of boulders surrounding the home-site and the number of crevices (Fig. 5). Similarly, Langkilde et al. (2007) measured variables relating to crevice dimensions (e.g. length, width and depth) and found them to differ significantly between home-sites supporting solitary juveniles and home-sites supporting juveniles living within family groups. The broad similarity between these studies is not surprising considering both species are related (Gardner et al. 2008) and occupy similar habitats. Thus, our data provide additional evidence to suggest that parental protection of offspring may be a causal factor in the social organi- 
zation of 'nuclear-type' lizard families, rather than access to better quality habitat.

We found home-site occupancy by lizard aggregations to be influenced by aspect and topography. Family groups were more abundant near the core (and often the peak) of the outcrop and on the northern aspects. Because E. striolata is a heliothermic species requiring access to solar radiation periodically throughout the day (Greer 1989), it is likely that elevated, core-area home-sites, that are exposed to maximum periods of solar radiation, increase the fitness of lizard groups. Lizards that are able to raise their core body temperature quickly, and safely, are more likely to be able to defend territories, forage and develop stable social groups.

\section{Summary}

This study used a novel approach of applying theoretical concepts traditionally used to explain patterns of biological diversity to investigate patterns of aggregation in E. striolata. We specifically examined the influence of geophysical and landscape attributes on patterns of lizard aggregation and spatial distribution in a naturally diverse, spatially-limited, non-biological system. We found granite inselberg type, landscape condition and home-site structure significantly influenced population dynamics and occupancy patterns of lizard home-sites. This study has clearly documented the environmental correlates of variability in sociality among subpopulations of $E$. striolata. Thus, our data contribute to the growing literature on the Egernia group and provide information that may establish a foundation from which future work on the broader mechanisms involved in the evolution of complex sociality in rock-dwelling vertebrates could be focused. Further studies are required to investigate social structuring and genetic relationships among family groups in our study area to help elucidate some of the conceptual questions we raise.

\section{ACKNOWLEDGEMENTS}

We gratefully acknowledge the numerous landholders in the region who allowed us access to the granite landforms on their properties. We also thank a number of volunteers for assisting with fieldwork, namely, Hugh MacGregor, Greg Slade and Nigel Jones. We also thank our colleagues for helping with aspects of the fieldwork, Mason Crane, Lachlan McBurney, Rebecca Montague-Drake and Rachel Muntz for preparing the location map. We thank the anonymous reviewer for making useful comments on an earlier draft. DM would also like to thank his family for support and encouragement.

\section{REFERENCES}

August P. V. (1983) The role of habitat complexity and heterogeneity in structuring tropical mammal communities. Ecology 64, 1497-507.

Bennett A. F., Radford J. Q. \& Haslem A. (2006) Properties of land mosaics: implications for nature conservation in agricultural environments. Biol. Conserv. 133, 25064.

Berry O., Tocher M. D., Gleeson D. M. \& Sarre S. D. (2005) Effect of vegetation matrix on animal dispersal: genetic evidence from a study of endangered skinks. Conserv. Biol. 19, 855-64.

Bonnett M. P. (1999) The ecology, behaviour and genetic relationships of a population of Egernia striolata (Honours Thesis). Flinders University of South Australia, Adelaide.

Bull C. M., Griffin C. L., Bonnett M., Gardner M \& Cooper S. J. B. (2001) Discrinination between related and unrelated individuals in the Australian lizard Egernia striolata. Behav. Ecol. Sociobiol. 50, 173-9.

Burke A. (2003) Inselbergs in a changing world - global trends. Divers. Distrib. 9, 375-83.

Bustard H. R. (1970) A population study of the scincid lizard Egernia. Proc. K. Ned. Akad. Wet. 73, 186-213.

Chapple D. G. (2003) Ecology, life-history, and behaviour in the Australian scincid genus Egernia, with comments on the evolution of complex sociality in lizards. Herpetol. Monogr. $17,145-80$.

Chapple D. G. \& Keogh J. S. (2006) Group structure and stability in social aggregations of White's Skink Egernia whitii. Ethology 112, 247-57.

Cogger H. G. (2000) Reptile and Amphibians of Australia. Reed New Holland, Sydney.

Cunningham R. B., Lindenmayer D. B., Crane M., Michael D. \& MacGregor C. (2007) Reptile and arboreal marsupial response to replanted vegetation in agricultural landscapes. Ecol. App. 17, 609-19.

Duffield G. A. \& Bull M. (2002) Stable social aggregations in an Australian lizard, Egernia stokesii. Naturwissenschaften 89, 424-7.

Fuller S. J., Bull C. M., Murray K. \& Spencer R. J. (2005) Clustering of related individuals in a population of the Australian Lizard, Egernia frerei. Mol. Ecol. 14, 120713.

Gardner M. G. (1999) A genetic investigation of sociality in the Australian group living lizard Egernia stokesii (PhD Thesis). Flinders University, Adelaide.

Gardner M. G., Bull M. C., Cooper S. J. B. \& Duffield G. A. (2001) Genetic evidence for a family structure in stable social aggregations of the lizard Egernia stokesii. Mol. Ecol. 10, $175-83$.

Gardner M. G., Bull M. C. \& Cooper S. J. B. (2002) High levels of genetic monogamy in the group-living Australian lizard Egernia stokesii. Mol. Ecol. 11, 1787-94.

Gardner M. G., Hugall A. F., Donnellan S. C., Hutchinson M. N. \& Foster R. (2008) Molecular systematics of the social skinks: phylogeny and taxonomy of the Egernia group (Reptilia: Scincidae). Zool. F. Linn. Soc. 154, 781-94.

Greer A. (1989) The Biology and Evolution of Australian Lizards. Surrey Beatty \& Sons, Sydney.

Gregory P.T. (1984) Communal denning in snakes. In: Vertebrate Ecology and Systematics: A Tribute to Henry S. Frith (eds R. A. Siegal, R. A. Seigel, L. E. Hunt, J. L. Knight, L. Malaret \& N. L. Zuschlag) pp. 57-75. University of Kansas Press, Kansas. 
Hall L. S., Krausmann P. R. \& Morrison M. L. (1997) The habitat concept and a plea for standard terminology. Wildl. Soc. Bull. 25, 173-82.

Langkilde T., O'Connor D. \& Shine R. (2007) Benefits of parental care: do junvenile lizards obtain better-quality habitat by remaining with their parents? Austral Ecol. 32, 950-4.

Lanham E. J. \& Bull C. M. (2004) Enhanced vigilance in groups in Egernia stokesii, a lizard with stable social aggregations. f. Zool. 263, 95-9.

Lindenmayer D. B. \& Fischer J. (2006) Habitat Fragmentation:An Ecological and Conservation Synthesis. Island Press, Washington, DC.

Lindenmayer D. B. \& Fischer J. (2007) Tackling the habitat fragmentation panchreston. Trends Ecol. Evol. 22, 127-32.

MacArthur R. H. \& MacArthur J. W. (1961) On bird species diversity. Ecology 42, 594-8.

McCullagh P. \& Nelder J. A. (1989) Generalized Linear Models. Chapman and Hall, New York.

McIntyre S. \& Hobbs R. (1999) A framework for conceptualizing human effects on landscapes and its relevance to management and research models. Conserv. Biol. 13, 1282-92.

Main A. R. \& Bull C. M. (1996) Mother-offspring recognition in two Australian Lizards, Tiliqua rugosa and Egernia stokesii. Anim. Behav. 52, 193-200.

Mares M. A. (1997) The geobiological interface: granitic outcrops as a selective force in mammalian evolution. f. $R$. Soc. WA 80, 131-9.

Masters C. \& Shine R. (2003) Sociality in lizards: family structure in free-living King's Skinks Egernia kingii from southwestern Australia. Aust. Zool. 32, 377-80.

Michael D. R., Cunningham R. B. \& Lindenmayer D. B. (2008) A forgotten habitat? Granite inselbergs conserve reptile diversity in fragmented agricultural landscapes. F. Appl. Ecol. $45,1742-52$.

Morrison M. L., Marcot B. G. \& Mannan R. W. (2006) Wildlifehabitat Relationships: Concepts and Applications. Island Press, Washington, DC.

O'Connor D. \& Shine R. (2003) Lizards in 'nuclear families': a noval reptilian social system in Egernia saxatilis (Scincidae). Mol. Ecol. 12, 743-52.
O'Connor D. \& Shine R. (2005) Kin discrimination in the social lizard Egernia saxatilis. Behav. Ecol. 17, 206-11.

Osterwalder K., Klingenbock A. \& Shine R. (2004) Field studies on a social lizard: home range and social organisation in an Australian skink, Egernia major. Austral Ecol. 29, 241-9.

Porembski S. \& Barthlott W. (2000) Inselbergs: Biotic Diversity of Isolated Rock Outcrops in Tropical and Temperate Regions. Ecological Studies 146, Springer-Verlag, Berlin.

Stamps J. A. (1977) Social behavior and spacing patterns in lizards. In: Biology of the Reptilia: Ecology and Behaviour, Vol 7 (eds C. Gans \& D. W. Tinkle) pp. 265-334. Academic Press, New York.

Stow A. J. \& Sunnucks P. (2004a) High mate and site fidelity in Cunningham's skink (Egernia cunninghami) in natural and fragmented habitat. Mol. Ecol. 13, 419-30.

Stow A. J. \& Sunnucks P. (2004b) Inbreeding avoidance in Cunninghams skink (Egernia cunninghami) in natural and fragmented habitat. Mol. Ecol. 13, 443-7.

Stow A. J., Sunnucks P., Briscoe D. A. \& Gardner M. G. (2001) The impact of habitat fragmentation on dispersal of Cunningham's skink (Egernia cunninghami): evidence from allelic and genotypic analyses of microsatellites. Mol. Ecol. 10, $867-78$.

Tews J., Brose U., Grimm V. et al. (2004) Animal species diversity driven by habitat heterogeneity/diversity: the importance of keystone structures. F. Biogeogr. 31, 7992.

Twidale C. R. \& Vidal Romani J. R. (2005) Landforms and Geology of Granite Terrains. A.A. Balkema Publishers, London.

Wilson S. \& Swan G. (2008) A Complete Guide to Reptiles of Australia. Reed New Holland, Sydney.

Withers P. C. \& Edward D. H. (1997) Terrestrial fauna of granite outcrops in Western Australia. F. R. Soc. WA 80, 159-66.

Zack S. \& Stutchbury B. J. (1992) Delayed breeding in avian social systems: the role of territory quality and 'floater' tactics. Behaviour 123, 194-219. 